418. Adolf Basler: Beiträge etc. - J. Bernstein: Berichtigung etc.

Fig. 3. Negative Schwankung bei Strychninkontraktionen des rechten Gastrocnemius einer kleineren männlichen Rana temp. Die einzelnen Ausschläge des Fadens sind vollständig voneinander getrennt. Versuch vom 29 . Oktober 1907.

Fig. 4. Negative Schwankung bei Strychninkontraktion des rechten Gastrocnemius einer kleineren männlichen Rana temp. Die Fadenkurven gehen ohne Panse direkt ineinander über. Versuch wie bei Fig. 3.

Fig. 5. Negative Schwankung bei Strychnineinzelkontraktionen des rechten Gastrocnemius einer kleineren weiblichen Rana esc. Der Muskel befindet sich schon im Stadium der Ermüdung, wie aus der Verkürzungskurve zn ersehen ist. Die negative Schwankung hat sich dabei nicht geändert. Versuch vom 23. Oktober 1907.

\author{
Berichtigung \\ zu dem Aufsatz, betitelt: „Zur Thermodynamik der Muskel- \\ kontraktion". Dieses Archiv Bd. 122 S. 129. \\ Von
}

\title{
J. Bermstein.
}

In obiger Arbeit ist auf S. 160 ein sinnentstellender Druckfehler stehen geblieben. Zeile 15 muss es heissen: „Bei ermüdender (statt "verminderter") Muskeltätigkeit, bei welcher die O-Zufuhr mit dem Verbrauch nicht ("nicht" ist fortgelassen) gleichen Schritt halten kann, wird man daher viel Milchsäure vorfinden." Ferner ist S. 175 Zeile 10 zwischen den Worten "Muskellänge" und „beträchtlich" ein "nicht" einzuschieben. 